\title{
Obstetric intensive care admissions at a tertiary hospital in Limpopo Province, South Africa
}

T S Ntuli, ${ }^{1}$ BSc, BsC (Hon), MSc; G Ogunbanjo, ${ }^{2}$ MB ChB, FCCS (SA), FACRRM, FAFP (SA); S Nesengani, ${ }^{3}$ MB ChB, MMed (O\&G);

E Maboya, ${ }^{4} \mathrm{MB} \mathrm{ChB}$, MMed (Anaes); M Gibango, ${ }^{4} \mathrm{MB} \mathrm{ChB}, \mathrm{MMed}$ (Anaes)

${ }^{1}$ Research Development and Administration, University of Limpopo (Turfloop Campus), Sovenga, South Africa

${ }^{2}$ Department of Family Medicine, Sefako Makgatho Health Sciences, University of Pretoria, South Africa

${ }^{3}$ Department of Obstetrics and Gynaecology, University of Limpopo (Turfloop Campus), Polokwane, South Africa

${ }^{4}$ Department of Anaesthesiology, University of Limpopo (Turfloop Campus), Polokwane, South Africa

Corresponding author: TS Ntuli (tsntuli@hotmail.com)

\begin{abstract}
Objective. To determine the characteristics of obstetric patients admitted to the intensive care unit (ICU) at a tertiary hospital in the Limpopo Province, South Africa.

Methods. Hospital files of all obstetric patients admitted to the Pietersburg provincial referral hospital ICU from 1 January 2008 to 31 December 2012 were retrospectively reviewed. Age, parity, admission diagnosis, length of stay, information on the referring hospitals, and maternal outcomes were analysed.

Results. There were 138 obstetric ICU admissions during the study period ( $6.7 \%$ of all ICU admissions and $0.95 \%$ of all deliveries). The most common reasons for obstetric ICU admissions were pre-eclampsia or eclampsia $(52.9 \%, n=73 / 138)$ and obstetric haemorrhage $(18.1 \%, n=25 / 138)$. The mean age of the patients was 28 years, and mean duration of ICU stay was 8 days (range 0 - 163 days). Forty-eight maternal deaths occurred (34.8\%), and of these, 27 were referrals from other hospitals (district and regional hospitals). Pre-eclampsia or eclampsia accounted for 25 ( $52 \%$ ) of all deaths. Conclusion. Obstetric patients formed a small proportion of ICU admissions, but mortality among these patients was high. It is recommended that obstetric registrars rotate through a multidisciplinary ICU, and the need for a critical care specialist should be considered.
\end{abstract}

S Afr J Crit Care 2015;31(1):8-10. DOI:10.7196/SAJCC.164

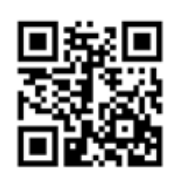

Admission of critically ill obstetric patients to the intensive care unit (ICU) is a common phenomenon in both developed and developing countries. A number of studies have reported that $<1 \%$ of ICU admissions are obstetric patients, ${ }^{[1-4]}$ while other studies indicate that ICU admission rates of $1-10 \%$ are obstetric patients. ${ }^{[5-7]}$ However, there are few studies in which obstetric patients comprise $>10 \%$ of ICU admissions. ${ }^{[8,9]}$ The most common reasons for obstetric admission are pre-eclampsia or eclampsia, and obstetric haemorrhage. ${ }^{[1,3,8,10-12]} \mathrm{A}$ few studies report that single and multiple organ failure may also be as a possible reason for obstetric admission. ${ }^{[8,13]}$

In the last 10 years, maternal mortality in the ICU is increasingly rare in developed countries, and some studies have reported no maternal deaths at all. ${ }^{[2,11,14]}$ Other studies have reported maternal mortality of between 1 and $5 \%,{ }^{[2,12]}$ while others have reported a maternal mortality of $>10 \% \cdot{ }^{[8,10,15-17]} \mathrm{A}$ retrospective study of obstetric patients admitted to the former Johannesburg General Hospital ICU reported a maternal death rate of $38 \% .{ }^{[18]}$ The ICU of the Obstetrics and Gynaecology Department in King Edward VIII Hospital, Durban, has reported a maternal mortality of $21 \% .^{[5]}$

The studies reviewed illustrate that there is a wide variation in the mortality rates of obstetric patients admitted to the ICU. Tertiary referral centres usually admit more high-risk obstetric patients ${ }^{[5,18]}$ In order to assist local healthcare teams in knowing which health conditions to focus on, there is a need to identify the indication for obstetric ICU admission. Therefore, a retrospective descriptive study was undertaken to determine the characteristics of obstetric patients admitted to a tertiary hospital in the Limpopo Province, South Africa (SA).

\section{Methods}

A retrospective review of obstetric admissions to the ICU of Pietersburg Hospital, Limpopo, SA, was carried out over a period of 5 years (1 January 2008 to 31 December 2012). The 12-bed multidisciplinary ICU admitted 350 - 450 patients on average per annum. ICU admission in this institution is based on the clinical judgment of the admitting discipline in consultation with an anaesthetist.

The ICU records and patient files were extracted and reviewed. Ethics approval to conduct the study was obtained from the University of Limpopo ethics committee, and anonymity and confidentiality of patient personal information were protected. The data for the study were collected by a trained nurse assistant. The data collected included patient age, parity, admission diagnosis, length of stay in the ICU and maternal outcome. Categorical data were displayed as percentages; continuous data were reported as mean (standard deviation (SD)). Statistical software (STATA 9.0, StataCorp, USA) was used for data analysis.

\section{Results}

Over the 5-year period, 138 obstetric patients were admitted (6.7\% of 2073 ICU admissions and $0.95 \%$ of 14478 deliveries at the hospital). Six patients were admitted twice, and two of these patients died. The characteristics of the admitted obstetric patients are presented in Table 1. The average age of the patients was 28 (8.1) years (range $16-45$ years). More than half $(n=79 / 138)$ of the patients had a parity of 2 or more. Sixtytwo patients (45\%) were referred, and the majority of the referred patients were from district hospitals $(n=53 / 62(86 \%))$. Table 2 shows the yearly obstetric deliveries and maternal ICU admissions from 2008 to 2012.

The indications for admission and outcome of obstetric ICU admissions are shown in Table 3. Pregnancy-induced hypertension $(52.9 \%, n=73 / 138)$ and severe obstetric haemorrhage $(18.1 \%$, 
$n=25 / 138$ ) were the most frequent causes of admission. Eleven of the patients with pre-eclampsia or eclampsia presented

\begin{tabular}{ll}
$\begin{array}{l}\text { Table 1. Characteristics of obstetric } \\
\text { patients admitted to the ICU }\end{array}$ \\
\hline \multicolumn{2}{l}{$\boldsymbol{n}(\%)$} \\
\hline Age (years) \\
$<20$ \\
$20-24$ & $22(16)$ \\
$25-29$ & $36(26)$ \\
$30-34$ & $33(24)$ \\
$35-39$ & $23(17)$ \\
$\geq 40$ & $16(11)$ \\
Parity (n) & $9(6)$ \\
0 & \\
1 & $39(29)$ \\
2 & $20(14)$ \\
$\geq 3$ & $53(38)$ \\
\end{tabular}

Table 2. Frequency of obstetric ICU admissions

\begin{tabular}{lll}
\hline Year & $\begin{array}{l}\text { Obstetric } \\
\text { deliveries, } \boldsymbol{n}\end{array}$ & $\begin{array}{l}\text { Obstetric ICU } \\
\text { admissions, } \boldsymbol{n}(\%)\end{array}$ \\
\hline 2008 & 3007 & $24(0.80)$ \\
2009 & 3037 & $27(0.89)$ \\
2010 & 2770 & $18(0.65)$ \\
2011 & 2758 & $45(1.63)$ \\
2012 & 2906 & $24(0.83)$
\end{tabular}

with HELLP (haemolysis, elevated liver enzymes and low platelet count) syndrome. Anaesthetic complications were seen in $5.8 \%(n=8 / 138)$ of the patients. The average duration of obstetric ICU admission was 8 days (range 0 - 163 days).

There were 48 obstetric deaths documented during the study period (mortality rate $34.8 \%$ ). This included $34 \%$ ( $n=25 / 73$ ) of the women admitted with pre-eclampsia or eclampsia and $36 \%$ $(n=9 / 25)$ of patients with severe obstetric haemorrhage. Half ( $n=24 / 48$ ) of the deaths were referrals from district hospitals.

\section{Discussion}

In our study, $6.7 \%$ of the ICU admissions were owing to obstetric problems. This finding is similar to those in studies with results that ranged between 1 and $10 \% \cdot{ }^{[5-7]}$ However, in some other studies obstetric ICU admission rates were reported to be $<1 \%$. ${ }^{[1-4]}$ The latter were exclusively conducted in developed countries, where obstetric care at peripheral referringhospitalsismuchimprovedcompared with that in developing countries.

Previous studies have reported that pre-eclampsia or eclampsia and obstetric haemorrhage were the most common indications for ICU admission. . $13,3,8,10-12]^{2}$ The findings of our study confirmed that these indications are the most frequent, although anaesthetic complications also

Table 3. Indications and outcomes of obstetric ICU admission ( $N=138)$

\begin{tabular}{|c|c|c|c|}
\hline Diagnosis & $\begin{array}{l}\text { Total, } \\
n(\%)\end{array}$ & $\begin{array}{l}\text { Survivors, } \\
n(\%)\end{array}$ & $\begin{array}{l}\text { Non-survivors, } \\
n(\%)\end{array}$ \\
\hline Pre-eclampsia or eclampsia & $73(52.9)$ & $48(66)$ & $25(34)$ \\
\hline Obstetric haemorrhage & $25(18.1$ & $16(64)$ & $9(36)$ \\
\hline Anaesthetic complication (spinal) & $8(5.8)$ & $5(62)$ & $3(38)$ \\
\hline Ruptured ectopic pregnancy & $4(2.9)$ & $3(75)$ & $1(25)$ \\
\hline Pulmonary oedema & $4(2.9)$ & $3(75)$ & $1(25)$ \\
\hline Renal failure & $4(2.9)$ & $2(50)$ & $2(50)$ \\
\hline Ruptured uterus & $4(2.9)$ & $3(75)$ & $1(25)$ \\
\hline Placenta abruptio & $3(2.2)$ & $2(67)$ & $1(33)$ \\
\hline Peripartum cardiomyopathy & $2(1.4)$ & $1(50)$ & $1(50)$ \\
\hline Respiratory distress & $2(1.4)$ & $2(100)$ & - \\
\hline Postabortional sepsis & $2(1.4)$ & $2(100)$ & - \\
\hline Abdominal pregnancy & $1(0.7)$ & $1(100)$ & - \\
\hline Bowel obstruction & $1(0.7)$ & - & $1(100)$ \\
\hline Hepatic encephalopathy & $1(0.7)$ & - & $1(100)$ \\
\hline Hypokalaemia & $1(0.7)$ & - & $1(100)$ \\
\hline Parasuicide & $1(0.7)$ & $1(100)$ & - \\
\hline Tuberculosis & $1(0.7)$ & - & $1(100)$ \\
\hline Septicaemia during labour & $1(0.7)$ & $1(100)$ & - \\
\hline
\end{tabular}

featured commonly. Other studies have shown that acute pulmonary oedema is also a frequent cause of admission to an $\mathrm{ICU}^{[2]}$ and a leading cause of death in women with pre-eclampsia. ${ }^{[19,20]}$ In our study, four patients were admitted owing to pulmonary oedema, and one succumbed to pre-eclampsia and multiple organ failure. Most of these conditions are preventable causes of maternal mortality and may indicate relative inexperience with regard to the early identification and management of obstetric emergencies. Interestingly, sepsis is one of the most common non-obstetric causes of admission into ICUs, accounting for $8-30 \% ;[1,12,21,22,23]$ however, in our study, only 4 (2.8\%) of the obstetric ICU admissions were owing to infectious causes. It is likely that most of these patients died without admission to ICU. ${ }^{[24]}$

In the present study, the average length of ICU stay was longer than that reported in previous studies. ${ }^{[1,3,10-12]}$ The reasons for this remain to be established; however, it is possible this was owing to admission of more severe obstetric cases from the referring hospitals. The management of obstetric patients in ICU is complex owing to the physiological changes due to pregnancy and poorly understood pathophysiology of pregnancy-related diseases such as preeclampsia, ${ }_{i}^{[25,26]}$ this requires collaboration between critical care specialists and obstetricians. $[21,27,28]$ In our study, $34.8 \%$ of patients admitted to the obstetric ICU died. This finding is similar to the Johannesburg Hospital study, which reported $38 \%,{ }^{[18]}$ but higher than the mortality rate reported in the Durban studies, i.e. $21 \%{ }^{[5,22]}$ Possible reasons for the high maternal mortality rate in our study are a lack of proper antenatal care, late referrals, poor transport facilities, limited specialist obstetrician and critical care specialist support, long distances to the referral hospital and inadequate emergency obstetric care at referral centres close to patient residences. To reduce this high maternal mortality rate, it would be necessary for the provincial health department to implement audit processes to identify areas for improvement in obstetric care at the district and regional referring hospitals within the province.

\section{Study limitations}

The duration of this study was only 5 years. A longer duration could have resulted in either a higher or lower maternal mortality rate from the obstetric ICU admissions at this hospital. As with retrospective studies, any missing data from patient files affect the reliability of the data, but this was minimised by reviewing all files from the records department and the ICU over the 
study period. Finally, in this 12-bed, multidisciplinary ICU, the severity of illness is assessed using the SOFA (Sequential Organ Failure Assessment) score; however, the scores were incomplete for obstetric ICU admissions.

\section{Conclusion}

In this 12-bed, multidisciplinary ICU, we found that obstetric patients form a small proportion of ICU admissions but the mortality is high. It is recommended that obstetric registrars rotatethrough a multidisciplinary ICU, and the need for a critical care specialist should be considered.

Acknowledgements. We thank the staff of the records department and ICU of the Pietersburg Hospital, especially Dr M E Gonzalez for her co-operation during this study.

\section{References}

1. Richa F, Karim N, Yazbeck P. Obstetric admissions to the intensive care unit: An eight year review. J Med Liban 2008;56(4):215-219.

2. Sriram S, Robertson MS. Critically ill obstetric patients in Australia: A retrospective audit of 8 years experience in a tertiary intensive care unit. Crit Care Resusc 2008;10(2):124.

3. Keizer JL, Zwart JJ, Meerman RH, Harinck BL, Feuth HD, Van Roosmalen J. Obstetric intensive care admissions: A 12-year review in a tertiary care centre. Eur J Obstet Gynecol Reprod Biol 2006;128(1-2):152-156. [http://dx.doi.org/10.1016/j.ejogrb.2005.12.013]

4. Ramachandra Bhat PB, Navada MH, Rao SV, Nagarathna G. Evaluation of obstetric admissions to intensive care unit of a tertiary referral center in coastal India. Indian J Crit Care Med 2013;17(1):34-37. [http://dx.doi.org/10.4103/0972-5229.112156]

5. Platteau P, Engelhadt T, Moodley J, Muckart DJ. Obstetric and gynaecological patients in an intensive care unit: A 1 year review. Trop Doctor 1997;27(4):2002-2006.

6. Cohen J, Singer P, Kogan A, Hod M, Bar J. Course and outcome of obstetric patients in a general intensive care unit. Acta Obstet Gynecol Scand 2000;79(10):846-850

7. Okafor UV, Aniebue U. Admission pattern and outcome in critical care obstetric patients. Int J Obstet Anesth 2004;13(3):164-166. [http://dx.doi.org/10.1016/j.ijoa.2004.04.002]

8. Vasquez DN, Estenssoro E, Canales HS, et al. Clinical characteristics and outcomes of obstetric patients requiring ICU admission. Chest 2007;131(3):718-724. [http://dx.doi.org/10.1378/chest.06-2388]

9. Mjahed K, Hamoudi D, Salmi S, Barrou L. Obstetric patients in a surgical intensive care unit: Prognostic factors and outcome. J Obstet Gynaecol 2006;26(5):418-423. [http://dx.doi. org/10.1080/01443610600720188

10. Baloch R, Jakhrani N, Zeb E, Hafeez F, Abassi M, Naz Abbasi F. Pattern and outcome of obstetric admissions to the surgical intensive care unit - A ten years study. J Surg Pakistan 2010;15(4)171-176.
11. Crozier TM, Wallace EM. Obstetric admissions to an integrated general intensive care unit in a quaternary maternity facility. Aust N Z J Obstet Gynaecol 2011; 51(3):233-238. [http://dx.do org/10.1111/j.1479-828X.2011.01303.x]

12. Leung NY, Lau AC, Chan KK, Yan WW. Clinical characteristics and outcomes of obstetric patients admitted to the intensive care unit: A 10-year retrospective review. Hong Kong Med J 2010;16(1):18-25.

13. Muench MV, Baschat AA, Malinow AM, Mighty HE. Analysis of disease in the obstetric intensive care unit at a university referral center: A 24-months review of prospective data. J Reprod Med 2008:53(12):914-920

14. Madan I, Jain NJ, Grotegut C, Nelson D, Dandolu V. Characteristics of obstetric intensive care unit admissions in New Jersey. J Matern Fetal Neonatal Med 2009;22(9):785-790. [http://dx.doi. org/ 10.3109/14767050902874097]

15. Al Suleiman SA, Outub HO, Rahman J, Rahman MS. Obstetric admissions to the intensive care unit: $A$ 12 year review. Arch Gynecol Obstet 2006;274(1):4-8. [http://dx.doi.org/10.1007/s00404-004-0721-z]

16. Ghike S, Asegaonkar P. Why obstetric patients are admitted to intensive care unit? A retrospective study. J South Asian Feder Obstr Gynae 2012;4(2):90-92.

17. Bhadabe R, De' Souza R, More A, Harde M. Maternal outcomes in critically ill obstetric patients: A unique challenge. Indian J Crit Care Med 2012;16(1):8-16. [http://dx.doi.org/10.4103/0972-5229.94416]

18. Taylor R, Richards GA. Critically ill obstetric and gynaecological patients in the intensive care unit. S Afr Med J 2000;90(11):1140-1144.

19. Duley L, Williams J, Henderson-Smart DJ. Plasma volume expansion for treatment of women with pre-eclampsia. Cochrane Database Syst Rev 2000;(2):CD001805. [http://dx.doi. org/10.1002/14651858.CD001805]

20. Ganzevoort W, Rep A, Bonsel GJ, et al. A randomised controlled trial comparing two temporising management strategies, one with and one without plasma volume expansion, for severe and early onset pre-eclampsia. BJOG 2005;112(10):1358-1368. [http://dx.doi. org/10.1111/j.1471-0528.2005.00687.x]

21. Zwart JJ, Dupuis JR, Richters A, Ory F, van Roosmalen J. Obstetric intensive care unit admission: A 2-year nationwide population-based cohort study. Intensive Care Med 2010;36(2):256-263. [http://dx.doi.org/10.1007/s00134-009-1707-x]

22. Ngene NC, Moodley J, Songca P. Maternal and fetal outcomes of HIV-infected and noninfected pregnant women admitted to two intensive care units in Pietermaritzburg, South Africa. S Afr Med J 2013;103(8):543-548. [http://dx.doi.org/10.7196/samj.6590]

23. Chawla S, Nakra M, Mohan S, Nambiar BC, Agarwal R, Marwaha A. Why do obstetric patients go to the ICU? A 3-year-study. Med J Armed Forces India 2013;69(2):134-137. [http://dx.doi. org/10.1016/j.mjafi.2012.08.033]

24. NCCEMD. Saving Mothers 2008-2010: Fifth Report on the Confidential Enquiries into Materna Deaths in South Africa - Short Report. http://www.doh.gov.za (accessed 1 October 2014).

25. Neligan PJ, Laffey JG. Clinical review: Special populations - critical illness and pregnancy. Crit Care 2011;15(4):227. [http://dx.doi.org/10.1186/cc10256]

26. Munnur U, Bandi V, Guntupalli KK. Management principles of the critically ill obstetric patient. Clin Chest Med 2011;32(1):53-60,viii. [http://dx.doi.org/10.1016/j.ccm.2010.10.003]

27. Cartin-Ceba R, Gajic O, lyer VN, Vlahakis NE. Fetal outcomes of critically ill pregnant women admitted to the intensive care unit for nonobstetric causes. Crit Care Med 2008;36(10):2746-2751.

28. South African Society of Anaesthesiologists. SASA Practice Guidelines 2013 - 2012, Revision. S Afr J Anaest Analg 2013;19(1):S1-S42. 